\title{
A biologically active peptide mimetic of $\mathbf{N}$-acetylgalactosamine/galactose Laura L Eggink* and J Kenneth Hoober
}

\author{
Address: Faculty of Biomedicine and Biotechnology, School of Life Sciences, Arizona State University, Tempe, AZ 85287-4501, USA \\ Email: Laura L Eggink* - leggink@asu.edu; J Kenneth Hoober - khoober@asu.edu \\ * Corresponding author
}

Published: II February 2009

BMC Research Notes 2009, 2:23 doi:10.1 I86/1756-0500-2-23

This article is available from: http://www.biomedcentral.com/1756-0500/2/23

(c) 2009 Eggink et al; licensee BioMed Central Ltd.

This is an Open Access article distributed under the terms of the Creative Commons Attribution License (http://creativecommons.org/licenses/by/2.0), which permits unrestricted use, distribution, and reproduction in any medium, provided the original work is properly cited.
Received: 3I October 2008

Accepted: II February 2009

\begin{abstract}
Background: Glycosylated proteins and lipids are important regulatory factors whose functions can be altered by addition or removal of sugars to the glycan structure. The glycans are recognized by sugar-binding lectins that serve as receptors on the surface of many cells and facilitate initiation of an intracellular signal that changes the properties of the cells. We identified a peptide that mimics the ligand of an $\mathrm{N}$-acetylgalactosamine (GalNAc)-specific lectin and asked whether the peptide would express specific biological activity.
\end{abstract}

Findings: A I2-mer phage display library was screened with a GalNAc-specific lectin to identify an amino acid sequence that binds to the lectin. Phage particles that were eluted from the lectin with free GalNAc were considered to have been bound to a GalNAc-binding site. Peptides were synthesized with the selected sequence as a quadravalent structure to facilitate receptor crosslinking. Treatment of human peripheral blood mononuclear cells for $24 \mathrm{~h}$ with the peptide stimulated secretion of interleukin-8 (IL-8) but not of IL-I $\beta$, IL-6, IL-I0, or tumor necrosis factor$\alpha($ TNF- $\alpha)$. The secretion of IL-2I was stimulated as strongly with the peptide as with interferon- $\gamma$.

Conclusion: The data indicate that the quadravalent peptide has biological activity with a degree of specificity. These effects occurred at concentrations in the nanomolar range, in contrast to free sugars that generally bind to proteins in the micro- to millimolar range.

\section{Background}

Many cells express cell-surface receptors that bind sugarcontaining ligands and serve important regulatory functions [1]. Extensive research over the past two decades has been devoted to design of peptide mimetics of sugars [2] to serve as vaccines that elicit anti-carbohydrate antibodies $[3,4]$ or to bind with high affinity to specific antibodies $[5,6]$. We asked whether a peptide mimetic of $\mathrm{N}$-acetylgalactosamine (GalNAc) could be identified that induces specific responses. For this purpose, a phage display library was screened with a GalNAc-specific lectin as a receptor analog. A consensus amino acid sequence emerged in the variable region of the pIII protein in the selected phage particles. Because clusters of GalNAc bind to receptors with higher affinity than a single residue [7], and receptor crosslinking is often required for many signal transduction mechanisms [8], we designed and tested a multivalent structure containing this sequence.

\section{Selection and synthesis of a GaINAc mimetic}

The lectin from Helix pomatia (HPA) binds O-linked $\alpha$ GalNAc but also recognizes Gal ( $\beta 1-3)$ GalNAc and $\alpha$ GlcNAc $[9,10] . K_{A}$ values for interactions of HPA with groups containing terminal GalNAc range from $0.1 \mathrm{mM}$ to 
$5 \mathrm{mM}$, within the range typical of binding of sugars to lectins [11]. HPA binds to the single O-linked $\alpha$-GalNAc on the serum macrophage activating factor (GcMAF) [12]. A M13 bacteriophage library consisting of randomized 12-mer sequences at the N-terminus of the PIII protein was screened for an amino acid sequence that would bind to this lectin. Bound phage particles were eluted from the lectin with free GalNAc to ensure specificity of selection. Table 1 lists amino acid sequences of the variable region of phage particles enriched by four cycles of selection, from which a consensus sequence, VQATQSNQHTPR, emerged. [An extensive screen of linear and disulfide-constrained 7-mer phage libraries failed to provide a consensus sequence (data not shown)].

The peptide was added to a tri-Lys core [13], which provided four identical sequences within the same structure (designated L4). A GGGS sequence, adjacent to the variable region in the pIII protein, was retained as a spacer to move the mimetic sequence away from the core. A dansyl group was attached to the sulfhydryl group of C-terminal Cys to provide a chromophore for determination of concentration and detection by fluorescence. The structure of the final product was [(VQATQSNQHTPRGGGS $\left.{ }_{2} \mathrm{~K}\right]_{2} \mathrm{~K}-$ $\beta A$-(S-dansyl)C (Fig. 1). The peptide was also synthesized with the C-terminal $\beta$ A-(S-dansyl)C replaced with $\varepsilon$-biotinyl-K. All peptides terminated with an amide group at the C-terminus.

The mass spectrum of dansylated L4 contained a signal for the singly-charged $(m+1)$ molecule of $7,310 \mathrm{Da}$, which was identical to the calculated mass of the protonated quadravalent structure (Fig. 1). The signal at $\mathrm{m} / \mathrm{z}=3,656$ Da corresponded to the doubly-charged peptide.

Table I: Amino acid sequences of the $\mathbf{N}$-terminus of protein PIII from separate phage plaques after 4 cycles of selection.

\begin{tabular}{|c|c|c|c|c|c|c|c|c|c|c|c|}
\hline A & $\mathbf{Q}$ & A & L & $\mathrm{G}$ & L & $S$ & $A$ & 1 & $S$ & $\mathbf{P}$ & $\mathbf{R}$ \\
\hline $\mathbf{V}$ & $\mathbf{Q}$ & $\mathbf{A}$ & $\mathbf{T}$ & $\mathbf{Q}$ & $\mathbf{S}$ & $\mathbf{N}$ & $\mathbf{Q}$ & H & $\mathbf{T}$ & $\mathbf{P}$ & $\mathbf{R}$ \\
\hline $\mathrm{E}$ & $\mathbf{Q}$ & $\mathbf{A}$ & $\mathbf{T}$ & $P$ & $R$ & $\mathbf{N}$ & $\mathrm{H}$ & $\mathrm{N}$ & $S$ & $\mathbf{P}$ & $P$ \\
\hline V & $\mathbf{Q}$ & A & $\mathbf{T}$ & $P$ & $\mathrm{R}$ & $\mathrm{L}$ & $\mathbf{Q}$ & $\mathbf{H}$ & $\mathbf{T}$ & $\mathbf{P}$ & $\mathbf{R}$ \\
\hline A & $\mathbf{Q}$ & G & $P$ & $P$ & $\mathbf{S}$ & $\mathrm{K}$ & $\mathbf{Q}$ & $\mathbf{H}$ & $S$ & $\mathbf{P}$ & $P$ \\
\hline $\mathbf{v}$ & $\mathbf{Q}$ & A & I & $\mathbf{Q}$ & $\mathbf{S}$ & $\mathbf{N}$ & $\mathbf{Q}$ & $\mathrm{L}$ & $\mathbf{T}$ & $\mathbf{P}$ & $\mathbf{R}$ \\
\hline $\mathbf{v}$ & $\mathbf{Q}$ & $\mathbf{A}$ & $\mathbf{T}$ & $\mathrm{T}$ & V & $\mathrm{Q}$ & I & $\mathrm{Q}$ & $\mathrm{H}$ & A & $P$ \\
\hline $\mathbf{V}$ & $\mathbf{Q}$ & $\mathbf{A}$ & $\mathrm{G}$ & $\mathbf{Q}$ & S & $\mathbf{N}$ & $A$ & H & $\mathbf{T}$ & A & G \\
\hline $\mathbf{v}$ & $\mathbf{Q}$ & A & $\mathbf{T}$ & $\mathbf{Q}$ & $\mathbf{S}$ & $\mathbf{N}$ & $\mathbf{Q}$ & $\mathbf{H}$ & $\mathbf{T}$ & $\mathbf{P}$ & $\mathbf{R}$ \\
\hline $\mathbf{V}$ & $\mathbf{Q}$ & A & $\mathrm{R}$ & $\mathbf{Q}$ & $\mathbf{S}$ & $\mathbf{N}$ & $\mathbf{Q}$ & $\mathbf{H}$ & $\mathbf{T}$ & $\mathbf{P}$ & $\mathbf{R}$ \\
\hline V & $\mathbf{Q}$ & $\mathrm{N}$ & $Y$ & $\mathbf{Q}$ & $\mathbf{S}$ & $\mathbf{N}$ & $\mathbf{Q}$ & H & $\mathbf{T}$ & $\mathbf{P}$ & $\mathbf{R}$ \\
\hline $\mathrm{T}$ & $F$ & $\mathbf{A}$ & $\mathbf{T}$ & $\mathbf{Q}$ & $\mathbf{S}$ & $\mathbf{N}$ & $\mathbf{Q}$ & $\mathbf{H}$ & $\mathbf{T}$ & $\mathbf{P}$ & $\mathbf{R}$ \\
\hline \multicolumn{12}{|c|}{ Consensus } \\
\hline $\mathbf{v}$ & $\mathbf{Q}$ & $\mathbf{A}$ & $\mathbf{T}$ & $\mathbf{Q}$ & $\mathbf{S}$ & $\mathbf{N}$ & $\mathbf{Q}$ & $\mathbf{H}$ & $\mathbf{T}$ & $\mathbf{P}$ & $\mathbf{R}$ \\
\hline
\end{tabular}

\section{Lectin binding}

Whether L4 expressed characteristics of a sugar was tested by two methods. Lectins whose primary specificities are GalNAc (Helix pomatia, HPA); GlcNAc or NeuNAc (wheat germ agglutinin, WGA); Gal [Griffonia (Bandeiraea) simplicifolia isolectin $\mathrm{B}_{4}, \mathrm{BS}$; ; and Man or Glc (concanavalin A, ConA), were fixed onto a glass slide. Non-specific sites were blocked with gelatin, and the slide was then incubated with biotin-tagged L4. Binding was detected by adding streptavidin labeled with the fluorescent dye Cy3. Lectins were spotted in triplicate to minimize conclusions from inaccurate delivery, as indicated by the top row of ConA. All four lectins bound L4, with strongest binding found with the Gal-specific lectin, BS (Fig. 2A). Binding was also observed with HPA and with WGA, which binds to clusters of GalNAc [14,15].

In a second assay, biotin-tagged L4 was first bound in wells of a microtiter plate coated with streptavidin, and the extent of binding was measured by activity of horseradish peroxidase conjugated to lectins that were retained in the wells. The Gal-specific lectin BS again bound most extensively to L4 (Fig. 2B). Binding of the lectins to a control peptide, synthesized with the spacer sequence repeated (i.e., VGGGSGGGS-), was not detected (Fig. 2B). These binding assays were designed to maintain maximal flexibility of the peptide. When adsorbed onto clean polystyrene surfaces of wells of a microtiter plate, as done in conventional solid-phase binding assays $[13,16]$, the arms of the peptide are most likely immobilized. In such assays, binding of BS was negligible while binding to WGA and ConA increased (data not shown).

\section{Biological activity of the mimetic peptide Cytotoxicity}

$\mathrm{L} 4$, from $3 \mathrm{nM}$ to $90 \mu \mathrm{M}$, did not affect the proliferation of human peripheral blood mononuclear cells (PBMCs) when measured by the incorporation of bromo-deoxyuridine into DNA over a 48 -h period (data not shown).

\section{Cytokine release}

Cytokines, which include interleukins (IL's) and chemokines, are regulatory proteins that are released from activated cells and act as intercellular mediators in the generation of a response. A preliminary survey to determine whether $\mathrm{L} 4$ induces a change in secretion of cytokines from human PBMCs indicated that IL-15, Eotaxin and TIMP-2 increased approximately two-fold over control levels in the culture medium in response to a 4-h treatment with $100 \mathrm{nM} \mathrm{L4}$. In contrast, the amounts of IL-2 and IL-8 in the medium were approximately half of that in the control culture that received phosphate-buffered saline (PBS), the vehicle, in place of the peptide solution. No significant changes were detected from control samples in the amounts of other cytokines, including IL- 


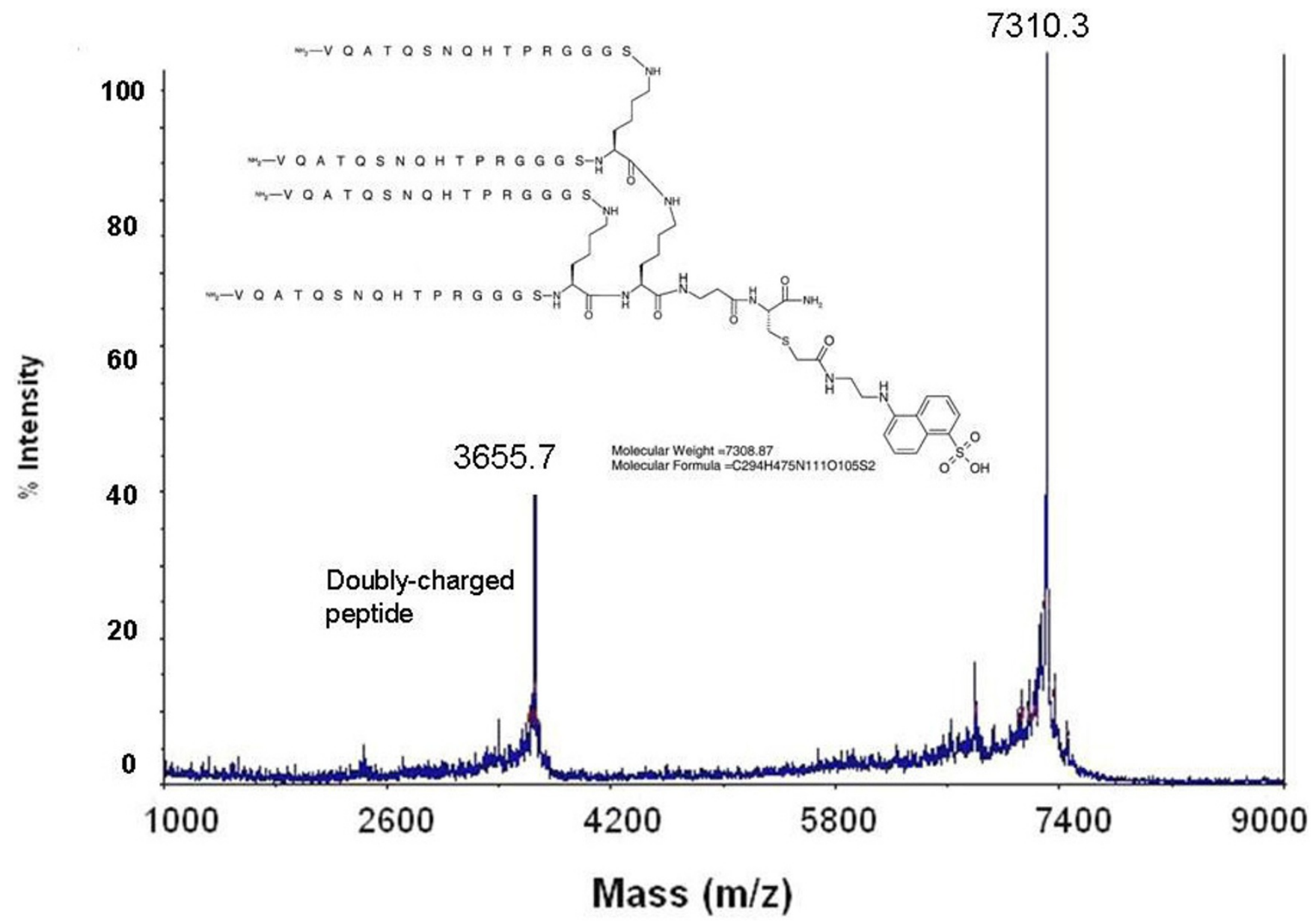

Figure I

Structure and mass spectrum of L4.

$1 \beta$, IL-6, IL-10, IFN- $\gamma$, or TNF- $\alpha$. After $24 \mathrm{~h}$ of treatment, IL-8, G-CSF, I-309 and Eotaxin-2 were significantly elevated in the medium (data not shown).

To quantitatively assess effects of L4 on cells, secretion of several key cytokines by PBMCs was assayed after incubation for $24 \mathrm{~h}$ with L4 or with lipopolysaccharide (LPS), the prototypic inflammatory agent, as a positive control. LPS (1 ng/ml) strongly stimulated secretion of cytokines IL$1 \beta$, IL-6, IL-8, IL-10 and TNF- $\alpha$. The peptide at relatively high concentrations (e.g., $30 \mu \mathrm{M}$ and $90 \mu \mathrm{M}$, Fig. 3A, B, D) weakly but significantly inhibited release of IL-1 $\beta$, IL-6 and TNF- $\alpha$ induced by LPS. The amounts of these cytokines in media of cultures treated with peptide alone were not significantly different from controls (Fig. 3A to $3 \mathrm{D})$. In contrast, secretion of IL- 8 was stimulated by the peptide nearly as strongly as with LPS, with maximal secretion at 3 and $300 \mathrm{nM} \mathrm{L4}$ (Fig. 3E). Higher concentrations, e.g., 3 to $30 \mu \mathrm{M}$, inhibited release of IL-8 as compared with the untreated, control level (light green bar).
IL-8 is a chemokine released from activated macrophages that attracts neutrophils and plays an important role in host defense by enhancing microbicidal activity and cytotoxicity $[17,18]$. For example, IL-8 dramatically reduced growth of human ovarian cancer cells and mediated effects of the chemotherapeutic drug paclitaxel by targeting neutrophils and monocytes to the tumor [18].

IL-21, a cytokine secreted from activated T cells, is of particular interest in regard to its pleiotropic immunomodulatory and anti-tumor activities $[19,20]$. A 16-h treatment of PBMCs with $50 \mathrm{nM}$ L4 induced as strong a release of IL21 as a highly effective concentration [ $1 \mathrm{nM}(400 \mathrm{U} / \mathrm{ml})]$ of IFN- $\gamma$, a known stimulant of IL-21 release [19] (Fig. 4). The low control value indicated that the peptide expressed an activity not provided by proteins and other factors from serum in the culture medium. IL-21 is most homologous to IL-15 and to a lesser extent IL-2. IL-21 has activity on all leukocyte subsets, including dendritic cells and 

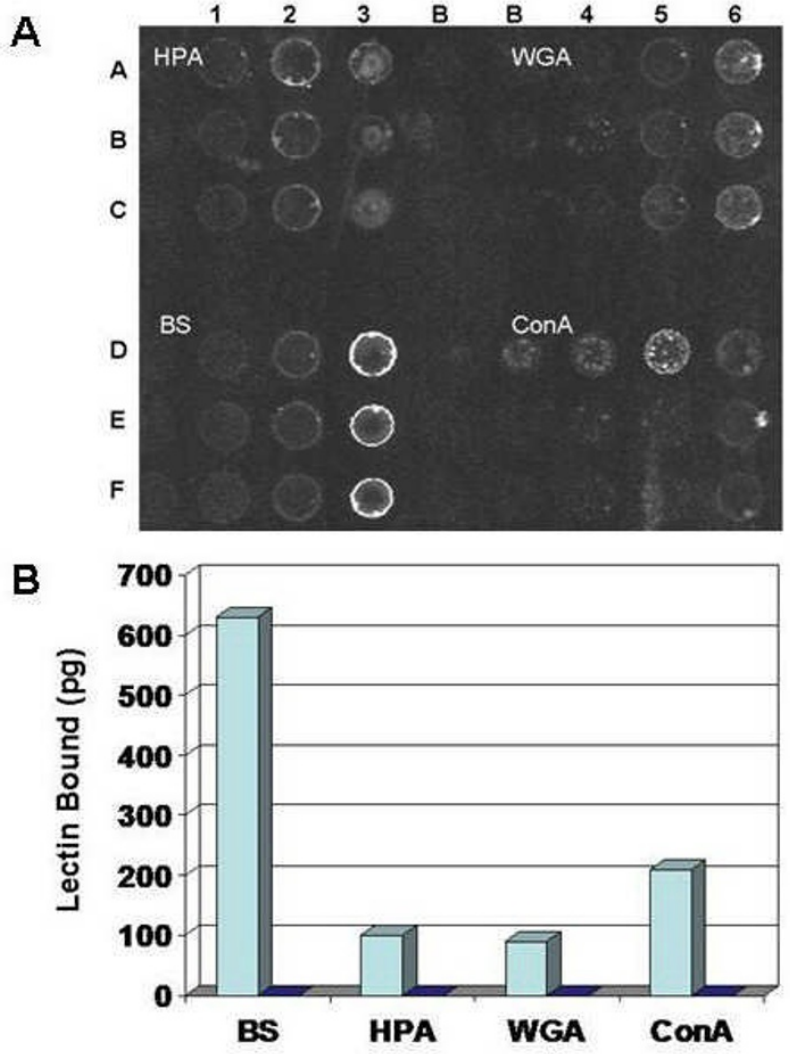

Figure 2

Binding of lectins to L4. (A) For each lectin, 4, 20 and 100 $\mathrm{ng}$ were spotted in triplicate. One set of a total of four sets is shown in the figure. Spots in rows A-C, columns I-3 contained $H$. pomatia lectin (HPA), rows A-C, columns 4-6 contained $T$. vulgare lectin (WGA), rows $D-F$, columns I-3 contained $B$. simplicifolia $B_{4}(B S)$ and rows $D-F$, columns 4-6 contained $C$. ensiformis lectin (ConA). The slide was incubated with $2 \%$ gelatin to block non-specific sites. Biotintagged peptide was incubated with the slide and then the amount of peptide bound was detected by binding of Cy3conjugated streptavidin and measuring fluorescence of the spots. In columns marked $B$, buffer $A$ was spotted as blanks. (B) Biotin-tagged L4 or control peptide was bound in wells of a streptavidin-coated microtiter plate. The wells were blocked with $2 \%$ gelatin, washed, and then equal amounts (50 $\mathrm{ng}$ ) of lectins conjugated with peroxidase were added. After washing, the amount of lectin bound was detected by peroxidase activity. Standard curves were determined with each lectin-peroxidase conjugate to quantitate binding. Data are expressed as the amount of lectin bound minus a blank without peptide. Light blue bars, peptide L4; dark blue bars, control peptide. monocytes [20]. IL-15 activates T cells and promotes longterm survival of memory $\mathrm{T}$ cells [21].

The control peptide, with the mimetic sequence replaced with VGGGSGGGS-, did not induce release of IL-8, IL-21 or other cytokines including IL-1 $\beta$, IL-6, IL-10, IFN- $\gamma$ and TNF- $\alpha$, (data not shown).

\section{Conclusion}

The multivalent peptide induced a remarkable pattern of cytokine release. Secretions of several cytokines that are used singly in clinical practice were stimulated, while release of highly inflammatory cytokines, such as IL-1 $\beta$, IL- 6 and TNF- $\alpha$, did not appear to be changed.

\section{Methods \\ Phage display library screening and DNA sequencing}

The Ph.D. ${ }^{\mathrm{TM}}-12$ phage display library (New England BioLabs, Ipswich, MA) was mixed with HPA conjugated to agarose beads (Sigma-Aldrich, St. Louis, MO) at room temperature in $200 \mu \mathrm{l}$ of $50 \mathrm{mM}$ Tris- $\mathrm{HCl}(\mathrm{pH} 7.5)$ containing $150 \mathrm{mM} \mathrm{NaCl}, 1 \mathrm{mM} \mathrm{CaCl}_{2}, 1 \mathrm{mM} \mathrm{MgCl}_{2}$ and 1 $\mathrm{mM} \mathrm{MnCl}_{2}$ (buffer A). The beads were washed three times and suspended in $1 \mathrm{ml}$ of buffer A. GalNAc was added to the suspension to $100 \mathrm{mM}$ and after $10 \mathrm{~min}$ the beads were removed by centrifugation. Phage released from the lectin were amplified by infection of E. coli strain ER2738 (New England BioLabs) and the screen was repeated three times. The buffer for the last cycle included $0.5 \%(\mathrm{w} / \mathrm{v})$ Tween 20. Phage released by GalNAc were plated on a lawn of E. coli and phage in individual plaques were amplified and DNA was sequenced with an Applied Biosystems 3730 Analyzer (Applied Biosystems, Foster City, CA) with the -96 gIII primer.

\section{Synthesis of peptides}

Quadravalent peptides were synthesized on a tri-Lys core [13] utilizing Fmoc (9-fluorenylmethoxycarbonyl)-protected amino acids and a Milligen Biosearch 9050+ continuous flow peptide synthesizer (Millipore, Billerica, $\mathrm{MA})$. The C-terminus consisted of $\beta \mathrm{Ala}(\beta \mathrm{A})$-Cys(C). A dansyl group was incorporated by reaction of the thiol group on C-terminal Cys with 5-(()(2iodoacetyl)amino)ethyl)amino)naphthalene-1-sulfonic acid (IAEDANS) (Molecular Probes, Eugene, OR). Biotin was incorporated into the peptide with C-terminal $\varepsilon$-biotinyl-Lys in place of $\beta$ Ala-Cys. A control peptide was synthesized with the sequence identified by phage display replaced with a repeat of the spacer sequence (i.e., VGGGSGGGS-). Peptides were purified on a preparative Jupiter Proteo C12 column (21.2 mm × $250 \mathrm{~mm}$ ) (Phenomenex, Torrance, CA) using a gradient from $8 \%$ to $18 \%$ acetonitrile in water containing $0.1 \%$ TFA, dried under vacuum, dissolved in sterile PBS, pH 7.2, and passed through a Sephadex G-25 or G-15 column $(1 \times 45 \mathrm{~cm})$ in 


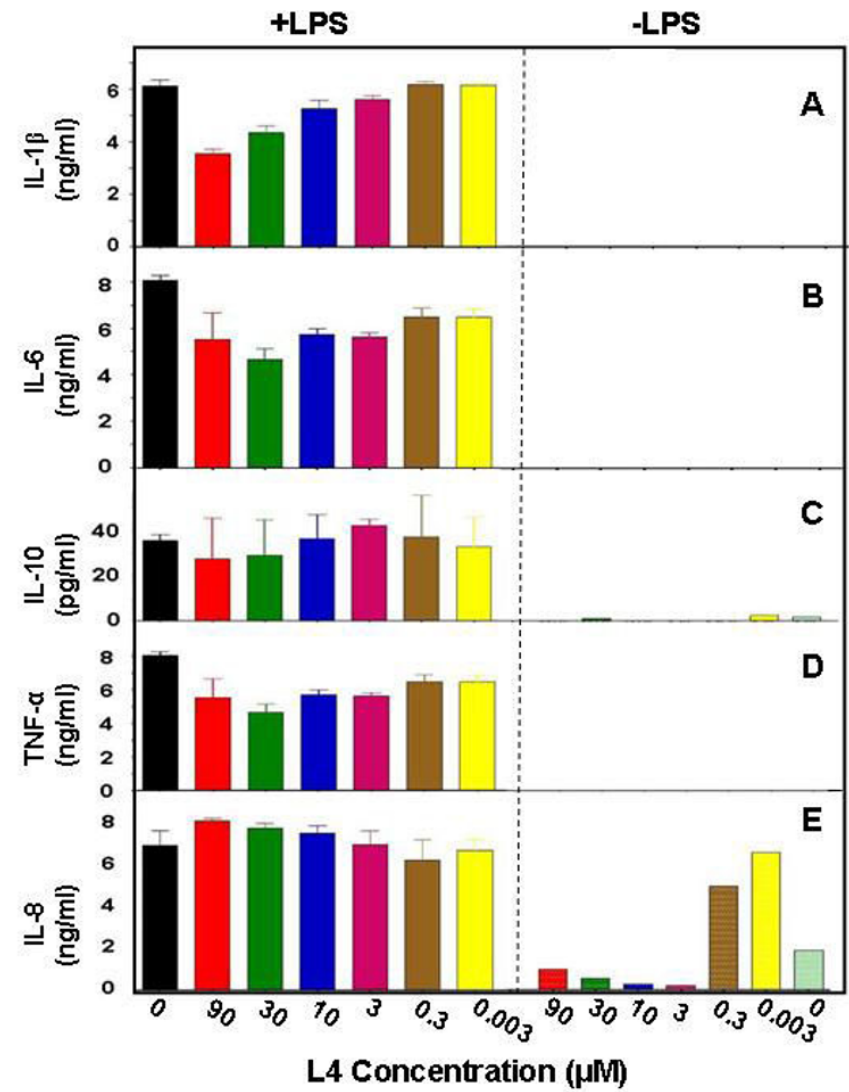

Figure 3

Quantitative analysis of cytokines. The amounts of several cytokines in media of PBMC cultures treated for $24 \mathrm{~h}$ with L4 in the presence of I ng/ml LPS (+LPS) or in the absence (-LPS) were determined. (A) IL-I $\beta$, (B) IL-6, (C) ILI0, (D) TNF- $\alpha$, and (E) IL-8. The concentration of L4 in each assay is indicated. Assays were done in quadruplicate.

PBS to remove TFA. Concentration was determined by absorbance of the dansyl group (extinction coefficient, $\varepsilon_{\mathrm{mM}}=5.7 \mathrm{~cm}^{-1}$ at $336 \mathrm{~nm}$ ) or by the bicinchoninic acid assay (Pierce, Rockland, IL) using known concentrations of the dansylated peptide as standard. Mass spectroscopy was performed with a Voyager DE STR mass spectrometer (Applied Biosystems).

\section{Lectin binding}

Horseradish peroxidase-conjugated lectins (SigmaAldrich) were prepared at a concentration of $500 \mu \mathrm{g} / \mathrm{ml}$ in buffer $A$ and $1 \mu$ l of each was spotted 4 times in triplicate onto a glass slide (Full Moon BioSystems, Sunnyvale, CA) at dilutions of 1:5, 1:25 and 1:125. Buffer A was spotted as blanks. The slide was blocked with $2 \%$ gelatin in buffer A, and biotin-tagged L4 in buffer A was incubated with the slide overnight at room temperature. The slide was washed 3 times with buffer A and then incubated with streptavidin conjugated with Cy3 (Sigma-Aldrich) for $1 \mathrm{~h}$.

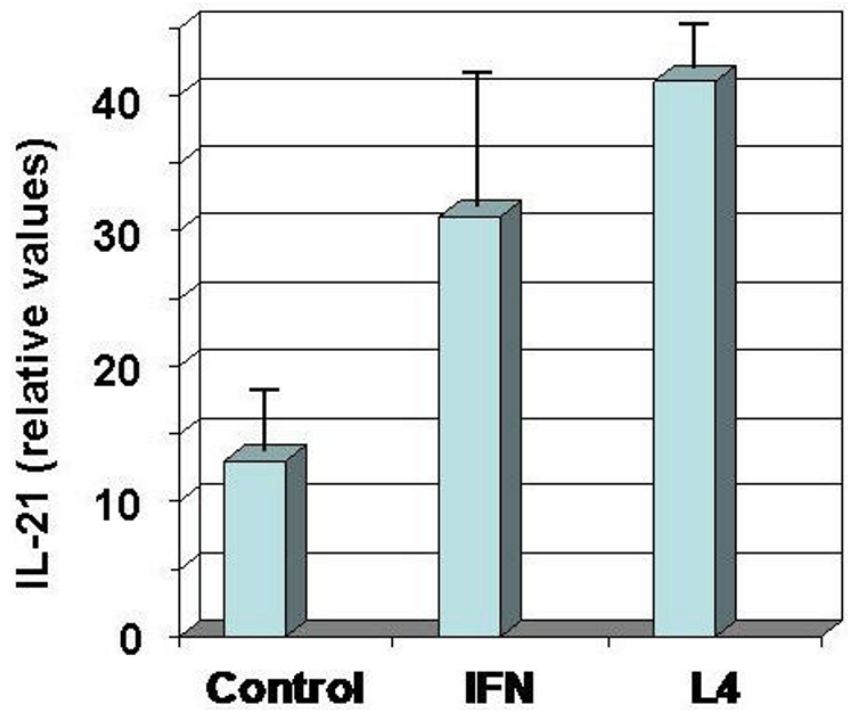

Figure 4

Stimulation of IL-2 I release from PBMCs by treatment with L4. PBMCs were treated with I nM (400 U/ml) IFN- $\gamma$ or $50 \mathrm{nM} \mathrm{L4}$ for $16 \mathrm{~h}$. The media were blotted onto membranes and stained with chicken anti-IL-2I antibodies and rabbit anti-chicken antibodies conjugated with peroxidase. The graph shows mean \pm SEM values of four measurements.

The slide was again washed 3 times with buffer A and fluorescence detected in a microarray reader.

For microtiter plate assays, $100 \mu \mathrm{l}$ of $2 \mu \mathrm{M}$ biotin-tagged L4 in PBS was added to each well of a high-binding-capacity streptavidin-coated plate (Pierce) and incubated overnight at $4{ }^{\circ} \mathrm{C}$. The wells were blocked with $2 \%$ gelatin in PBS for $3 \mathrm{~h}$ at room temperature, washed 1 time with PBS and then with buffer $A$. Lectins were added at a concentration of $1 \mu \mathrm{g} / \mathrm{ml}$ in buffer A. After $1 \mathrm{~h}$ incubation, wells were washed 4 times with buffer A containing $0.01 \%$ Tween-20, $50 \mu$ l peroxidase substrate (1-Step Ultra TMBELISA, Pierce) was then added, and after $5 \mathrm{~min}$ the reaction was stopped with $50 \mu \mathrm{l} 2 \mathrm{M} \mathrm{H}_{2} \mathrm{SO}_{4}$. Absorbance was read immediately at $450 \mathrm{~nm}$. Standard curves were obtained by assaying known amounts of the horseradish peroxidase-conjugated lectins $\left(\mathrm{OD}_{450} / \mathrm{ng}\right.$ protein).

\section{Cytokine assays}

Human PBMCs (Cellular Technology Ltd, Shaker Heights, $\mathrm{OH})$ were plated at $4 \times 10^{5}$ cells per well in RPMI 1640 medium containing $10 \%$ fetal bovine serum (FBS). After 2 days at $37^{\circ} \mathrm{C}$ in $5 \% \mathrm{CO}_{2}$, the medium was replaced and peptide or LPS added and the incubation continued for 24 h. Media were then withdrawn and cytokines assayed with BioSource kits (Invitrogen, Carlsbad, CA). For IL-21 analyses, media were applied to Immobilon-P membranes 
(Millipore) in a slot-blot apparatus, the membrane was blocked with 5\% nonfat dried milk in PBS, incubated with a primary chicken polyclonal anti-IL-21 antibody (Abcam, Cambridge, MA) and then with a rabbit polyclonal anti-chicken IgY antibody (Abcam) conjugated with horseradish peroxidase. Bound antibodies were detected with 3,3',5,5'-tetramethylbenzidine substrate (SigmaAldrich). Membranes were scanned with a densitometer to quantitate the extent of reaction.

\section{Abbreviations}

Gal: galactose; GalNAc: N-acetylgalactosamine; G-CSF: granulocyte colony-stimulating factor; Glc: glucose; GlcNAc: N-acetylglucosamine; IFN: interferon; Man: mannose; NeuNAc: sialic acid; PBMCs: peripheral blood mononuclear cells; PBS: phosphate-buffered saline; TNF: tumor necrosis factor.

\section{Authors' contributions}

LLE conceived of the concept of the peptide mimetic, designed the peptides, and performed most of the experimental work. LLE and JKH conducted biochemical studies and drafted the manuscript. The authors declare that they are inventors of technology owned by Arizona State University and the Arizona Board of Regents.

\section{Acknowledgements}

We gratefully knowledge the support and skill of Daniel Brune, Director, ASU Proteomics and Protein Chemistry Laboratory, and Scott Bingham, Director, ASU Nucleic Acid Facility, and the technical help of John Lopez, Valerie Jacobs, Laura Eheart and Srilakshmi Bysani. The quantitative cytokine assays were performed by BioQuant, San Diego, CA This work was supported by grants from the Wallace Research Foundation and the Arizona Biomedical Research Commission. NSF grant CHE-0I3। 222 provided funds to purchase the mass spectrometer.

\section{References}

I. Galustian C, Park CG, Chai W, Kiso M, Bruening SA, Kang YS, Steinman RM, Feizi T: High and low affinity carbohydrate ligands revealed by murine SIGN-RI by carbohydrate array and cell binding approaches, and differing specificities for SIGN-R3 and langerin. Internat Immunol 2004, I 6:853-866.

2. Oldenburg KR, Loganathan D, Goldstein IJ, Schultz PG, Gallop MA: Peptide ligands for a sugar-binding protein isolated from a random peptide library. Proc Natl Acad Sci USA 1992, 89:5393-5397.

3. Cunto-Amesty G, Dam TK, Luo P, Monzavi-Karbassi B, Brewer CF, Van Cott TC, Kieber-Emmons T: Directing the immune response to carbohydrate antigens. I Biol Chem 200I, 276:30490-30498.

4. Pashov AD, Plaxco J, Kaveri SV, Monzavi-Karbassi B, Harn D, KieberEmmons T: Multiple antigenic mimotopes of HIV carbohydrate antigens. Relating structure and antigenicity. J Biol Chem 2006, 28I:29675-29683.

5. Harris SL, Craig L, Mehroke JS, Rashed M, Zwick MB, Kenar K, Toone EJ, Greenspan N, Auzanneau F-I, Marino-Albernas J-R, Pinto BM, Scott JK: Exploring the basis of peptide-carbohydrate crossreactivity: evidence for discrimination by peptides between closely related anti-carbohydrate antibodies. Proc Natl Acad Sci USA 1997, 94:2454-2459.

6. Lang J, Zhan J, Xu L, Yan Z: Identification of peptide mimetics of xenoreactive $\alpha$-Gal antigenic epitope by phage display. Biochem Biophys Res Commun 2006, 344:214-220.
7. Dimick SM, Powell SC, McMahon SA, Moothoo DN, Naismith JH, Toone EJ: On the meaning of affinity: cluster glycoside effects and concanavalin A. J Am Chem Soc 1999, I 2 1:10286-10296.

8. Marsh CB, Lowe MP, Rovin BH, Parker JM, Liao Z, Knoell DL, Wewers MD: Lymphocytes produce IL-Ibeta in response to Fcgamma receptor cross-linking: effects on parenchymal cell IL-8 release. J Immunol I998, I 60:3942-3948.

9. Hammarström S, Kabat EA: Studies on specificity and binding properties of the blood group $A$ reactive hemagglutinin from Helix pomatia. Biochemistry 1971, I0:1684-1692.

10. Sanchez JF, Lescar J, Chazalet V, Audfray A, Gagnon J, Alvarez R, Breton C, Imberty A, Mitchell EP: Biochemical and structural analysis of Helix pomatia agglutinin: A hexameric lectin with a novel fold. J Biol Chem 2006, 28 I:2017I-20I80.

I I. Liang P-H, Wang S-K, Wong C-H: Quantitative analysis of carbohydrate-protein interactions using glycan microarrays: determination of surface and solution dissociation constants. J Am Chem Soc 2007, I 29: I I I77- I I I84.

12. Kanan RM, Cook DB, Datta HK: Lectin immunoassay for macrophage activating factor (Gc-MAF) produced by deglycosylation of Gc-globulin: evidence for noninducible generation of Gc-MAF. Clin Chem 2000, 46:4I2-4I4.

13. Posnett DN, McGrath H, Tam JP: A novel method for producing anti-peptide antibodies. J Biol Chem 1988, 263:1719-1725.

14. Wu AM, Wu JH, Song SC, Tsai MS, Herp A: Studies on the binding of wheat germ agglutinin (Triticum vulgaris) to O-glycans. FEBS Lett 1998, 440:315-319.

I5. Natsuka S, Kawaguchi M, Wada Y, Ichikawa A, Ikura K, Hase S: Characterization of wheat germ agglutinin ligand on soluble glycoproteins in Caenorhabditis elegans. J Biochem 2005, I38:209-2|3.

16. Afrough B, Dwek MV, Greenwell P: Identification and elimination of false-positives in an ELISA-based system for qualitative assessment of glycoconjugate binding using a selection of plant lectins. BioTechniques 2007, 43:458-462.

17. Baggiolini M, Loetscher P, Moser B: Interleukin-8 and the chemokine family. Int J Immunopharmacol 1995, I 7: I03-I08.

18. Lee LF, Hellendall RP, Wang Y, Haskill JS, Mukaida N, Matsushima K, Ting JPY: IL-8 reduced tumorigenicity of human ovarian cancer in vivo due to neutrophil infiltration. J Immunol 2000, I 64:2769-2775.

19. Brandt K, Singh PB, Bulfone-Paus S, Rückert R: Interleukin-2 I: a new modulator of immunity, infection, and cancer. Ctyokine Growth Factor Rev 2007, I 8:223-232.

20. Skak K, Kragh M, Hausman D, Smyth MJ, Sivakumar PV: Interleukin2 I: combination strategies for cancer therapy. Nature Rev Drug Discov 2008, 7:231-240.

2I. Shanmugham LN, Frydas CP, Donelan J, Castellani ML, Boucher W Madhappan B, Tete S, Falasca K, Conti P, Vecchiet J: IL- I 5 an immunoregulatory and anti-cancer cytokine. Recent advances. J Exp Clin Cancer Res 2006, 25:529-536.

Publish with Bio Med Central and every scientist can read your work free of charge

"BioMed Central will be the most significant development for disseminating the results of biomedical research in our lifetime. "

Sir Paul Nurse, Cancer Research UK

Your research papers will be:

- available free of charge to the entire biomedical community

- peer reviewed and published immediately upon acceptance

- cited in PubMed and archived on PubMed Central

- yours - you keep the copyright
BioMedcentral 